\title{
Clinical and Psychosocial Predictors of Community Reintegration of Stroke Survivors Three Months Post In-Hospital Discharge
}

\author{
Nelson EKECHUKWU ${ }^{1}$, Olubukola OLALEYE ${ }^{2}$, Talhatu HAMZAT ${ }^{2 *}$
}

OPEN ACCESS

Citation: Nelson Ekechukwui, Olubukola Olaleye, Talhatu Hamzat. Clinical and Psychosocial Predictors of Community Reintegration of Stroke Survivors Three Months Post In-Hospital Discharge. Ethiop J Health Sci 2017;27(1):27-34. doi:

http://dx.doi.org/10.4314/ejhs.v27i1.5

Received: May 29, 2016

Accepted: September 30, 2016

Published: January 1, 2017

Copyright: Neelson E, et al. This is an open access article distributed under the terms of the Creative Commons Attribution License, which permits unrestricted use, distribution, and reproduction in any medium, provided the original author and source are credited. Funding: Nil

Competing Interests: The authors declare that this manuscript was approved by all authors in its form and that no competing interest exists.

Affiliation and Correspondence:

${ }^{1}$ Department of Medical

Rehabilitation, College of Medicine, University of Nigeria, Enugu, Nigeria ${ }^{2}$ Department of Physiotherapy, College of Medicine, University of Ibadan, Ibadan, Nigeria

*Email: tkhamzat@com.ui.edu.ng; talkzat@yahoo.com

\begin{abstract}
BACKGROUND: There appears to be a dearth of published literature on the biopsychosocial predictors of community reintegration (CR) among stroke survivors. This study aims to investigate the clinical and psychosocial predictors of $C R$ among stroke survivors three months post in-hospital discharge.

METHODS: Fifty-two stroke survivors took part in this prospective exploratory study. The participants' clinical attributes of motor function (MF), balance (Bal) and psychosocial characteristics of Fall Self- Efficacy (FSE), Balance Self-Efficacy (BSE), SelfEsteem (SEst) and Social Support (SS) were assessed pre-discharge and at three months post-discharge. CR was also assessed at three months post-discharge. Data were analyzed using paired t-test, Pearson's Moment correlation and multiple regressions. Level of significance was set at $p=0.05$

RESULTS: The mean age of the participants was $61.21 \pm 11.25$ years with mean hospital length of stay of 5.31+3.71weeks. There were significant differences in the mean MF, Bal, FSE, BSE, SEst and SS scores of the participants pre- and post-discharge ( $p<$ 0.05). Also, there was a significant correlation between $C R$ and each of MF, Bal, FSE, BSE, SEst and SS. Pre-discharge Age ( $\beta=$ $0.226, p=0.001)$ and $F S E(\beta=1.387, p=0.040)$ significantly predicted CR. Post-discharge age $(\beta=-0.164, p=0.005)$ and Bal $(\beta$ $=0.142, p=0.048)$. FSE $(\beta=1.243, p=0.034)$ also significantly predicted $C R$.

CONCLUSION: Age, Bal and FSE are important predictors of CR among stroke survivors. Therefore, rehabilitation programmes should focus on improving Bal and FSE in order to enhance community reintegration among stroke survivors.
\end{abstract}

KEYWORDS: Clinical Attributes, Psychosocial Characteristics, Community Reintegration, Stroke Survivors

\section{INTRODUCTION}

Stroke is the second leading cause of death globally. It is a major cause of activity limitation as well as participation restriction among survivors (1). Reports (2,3) suggested an increasing incidence of stroke in Nigeria. The frequency of stroke in hospital populations varied from $0.9 \%$ to $4.0 \%$, and it accounted for $0.5 \%$ to $45 \%$ of 
neurological admissions (3). Stroke accounted for $5 \%$ to $17 \%$ of medical deaths in Nigeria $(2,3)$. Therefore, stroke is a significant health problem in Nigeria and places a huge burden on the health services in the country. Rehabilitation plays an important role in reducing the burden of disability associated with stroke (4). One of the key elements and aims of stroke rehabilitation is community reintegration $(4,5)$.

Community reintegration, an integral part of the concept of participation (6), is often the most underestimated component of stroke rehabilitation (7). It marks the end of rehabilitation for most professionals in the field of stroke rehabilitation. The characteristics of a person's environment such as social support affect participation after stroke (8). Therefore, in addition to promoting physical recovery (clinical attributes), a major goal of stroke rehabilitation is to minimize psychosocial morbidity (psychosocial characteristics) in order to promote the reintegration of stroke survivors into their family and community. There appears to be a dearth of published literature on the biopsychosocial predictors of community reintegration among Nigerian stroke survivors before and after the discharge from in-patient care into the communities. This study investigated the clinical and psychosocial predictors of community reintegration of stroke survivors three months post in-patient discharge.

\section{METHODS}

Study Design: A prospective exploratory study was used. The minimum sample size was calculated using the expression of medium effect: $\mathrm{n}=\mathrm{N}\left(\mathrm{Z}_{1}+\mathrm{Z}_{2}\right)^{2} / \mathrm{ES}^{2}+10 \%$ expected attrition; where $\mathrm{n}=$ minimum sample size, $\mathrm{N}=$ number of groups $=1, Z_{1}=\alpha$ - confidence interval at $0.05=$ $1.96, Z_{2}=\beta$ - confidence interval at $0.02=0.84$, and $\mathrm{ES}=$ medium effect of 0.4 .

Fifty-five stroke survivors were recruited into this study from three tertiary hospitals in three geopolitical zones in Nigeria. Stroke patients with cognition deficit or any other known neurological impairment(s) were excluded from the study. However, only 52 stroke survivors completed the study.
Instruments: Reintegration to Normal Living Index was used to assess community reintegration of participants (9). State Self-Esteem Scale (10), Social Support Questionnaire (11), ActivitySpecific Balance Confidence Scale (12) and Fall Efficacy Scale (13) were used to assess selfesteem, perceived social support, balance selfefficacy and fall self-efficacy of the participants respectively. The Fugl-Meyer Assessment Scale (14) and Berg Balance Scale (15) were used to assess motor function and balance among the participants respectively.

Procedure: Ethical approval for the study was obtained from the respective ethical committees of the three tertiary hospitals from which participants were recruited. The procedure for the study was explained to the patients before obtaining their informed consent. Medical history and demographic variables of participants were obtained from their case notes and/or through interview. The clinical attributes of motor function (MF1), balance (Bal1) and psychosocial attributes of Balance Self-Efficacy (BSE1), Fall SelfEfficacy (FSE1), Self-Esteem (SEst1) and Social Support (SS1) of the participants were measured at the point of in-patient discharge (pre-discharge). The level of community reintegration (CR) was assessed at three months post-discharge along with the clinical attributes of motor function (MF2) and balance (Bal2). Similarly, the psychosocial attributes of Balance Self-Efficacy (BSE2), Fall Self-Efficacy (FSE2), Self-Esteem (SEst2) and Social Support (SS2) were assessed three months after in-patient discharge.

Data analyses: The data were analyzed using SPSS package version 20.0. Descriptive statistics of mean, standard deviation and percentages were used to summarize the data. Pearson's Moment correlation coefficient was used to evaluate the association between community reintegration and each of the clinical and psychosocial attributes at the points of discharge from in-patient facility and three months after discharge from the health facility. Partial correlation was used to adjust for the influence of patients' physical characteristics. Multiple regression analysis was used to identify the predictors of community reintegration pre- and three months post-discharge. The level of significance was set at $\mathrm{p}=0.05$.

DOI: http://dx.doi.org/10.4314/ejhs.v27i1.5 


\section{RESULTS}

A total of 55 stroke patients (26 males, 29 females) were recruited for this study. However, only 52 ( 25 males, 27 females) completed the study. One of the participants had a second stroke while the other two changed their places of residence outside the location of study. The mean age of the participants was $61.21 \pm 11.25$ years with

Table 1: Demographic Characteristics of the Patients $(\mathrm{N}=52)$.

\begin{tabular}{|c|c|c|c|}
\hline Variable & Category & $\mathbf{n}$ & $\%$ \\
\hline \multicolumn{4}{|l|}{ Location } \\
\hline & Port Harcourt & 24 & 46.2 \\
\hline & Enugu & 17 & 32.7 \\
\hline & Ibadan & 11 & 21.2 \\
\hline \multicolumn{4}{|l|}{ Gender } \\
\hline & Male & 25 & 48.1 \\
\hline & Female & 27 & 51.9 \\
\hline \multicolumn{4}{|c|}{ Occupation } \\
\hline & Farmer & 5 & 9.6 \\
\hline & Trader & 11 & 21.2 \\
\hline & Businessman/woman & 10 & 19.2 \\
\hline & Retiree & 8 & 15.4 \\
\hline & Civil Servant & 18 & 34.6 \\
\hline \multicolumn{4}{|c|}{ Age (years) } \\
\hline & $30-39$ & 3 & 5.8 \\
\hline & $40-49$ & 2 & 3.9 \\
\hline & $50-59$ & 18 & 34.6 \\
\hline & $60-69$ & 16 & 30.8 \\
\hline & $70-79$ & 10 & 19.2 \\
\hline & $80-89$ & 3 & 5.8 \\
\hline \multicolumn{4}{|c|}{ Type of Stroke } \\
\hline & Ischaemic & 38 & 73.1 \\
\hline & Haemorrhagic & 14 & 26.9 \\
\hline \multicolumn{4}{|c|}{ Laterality of Stroke } \\
\hline & Right & 29 & 55.8 \\
\hline & Left & 23 & 44.2 \\
\hline \multicolumn{4}{|c|}{ Occurrence of stroke } \\
\hline & Once & 46 & 88.5 \\
\hline & Twice & 6 & 11.5 \\
\hline \multicolumn{4}{|c|}{ Duration of Stay in hospital ward(weeks) } \\
\hline & $0.0-2.0$ & 6 & 11.5 \\
\hline & $3.0-5.0$ & 30 & 57.7 \\
\hline & $6.0-9.0$ & 11 & 21.2 \\
\hline & $10.0-13.0$ & 4 & 7.7 \\
\hline & $>13.00$ & 1 & 1.9 \\
\hline \multicolumn{4}{|c|}{ Duration of PT before discharge (weeks) } \\
\hline & $0.0-2.0$ & 27 & 51.9 \\
\hline & $3.0-5.0$ & 20 & 38.5 \\
\hline & $6.0-9.0$ & 5 & 9.6 \\
\hline
\end{tabular}

age range of $31-86$ years. The mean length of hospital stay was $5.31 \pm 3.71$ weeks (Table 1 ).

The mean MF1 and Bal1 scores were $24.02 \pm 20.01$ and $9.9 \pm 5.59$ respectively while the mean MF2 and Bal2 scores were 62.81 \pm 22.05 and $36.27 \pm 10.95$ in that order. There was a significant difference between the MF1 and MF2 and between Bal1 and Bal2 scores ( $p<0.001)$ of the

DOI: http://dx.doi.org/10.4314/ejhs.v27i1.5 
participants. Similarly, there was a significant

variables pre- and post-discharge (Table 2).

difference $\quad(p<0.05)$ between psychosocial

Table 2: Comparison of the Pre-Discharge and Post-Discharge Variables of the Participants $(\mathrm{N}=52)$.

\begin{tabular}{lllllll}
\hline Variables & & Mean & S.D & t & df & Sig. (2-tailed) \\
\hline \multirow{2}{*}{ MF Pair } & MF1 & 24.02 & 20.01 & -17.77 & 51 & $0.0001^{*}$ \\
& MF2 & 62.81 & 22.05 & & & \\
BAL Pair & BAL1 & 9.94 & 5.59 & -18.25 & 51 & $0.0001^{*}$ \\
& BAL2 & 36.27 & 10.95 & & & \\
FSE Pair & FSE1 & 3.18 & 1.64 & -18.60 & 51 & $0.0001^{*}$ \\
& FSE2 & 6.30 & 1.35 & & & \\
BSE Pair & BSE1 & 24.16 & 15.97 & -15.25 & 51 & $0.0001^{*}$ \\
& BSE2 & 52.26 & 14.10 & & & \\
SEst Pair & SEst1 & 58.6346 & 10.15 & -13.46 & 51 & $0.0001^{*}$ \\
& SEst2 & 74.1731 & 8.68 & & & \\
SS Pair & SS1 & 2.4844 & 1.28 & -3.22 & 51 & $0.002^{*}$ \\
\hline
\end{tabular}

$*$ Significant difference at $\mathrm{p}=0.05$, FSE1 $=$ Fall Self Efficacy pre-discharge, FSE2 $=$ Fall Self Efficacy post-discharge, BSE1 $=$ Balance Self Efficacy pre-discharge, BSE2 = Balance Self Efficacy post-discharge, SEst1 = Self Esteem pre-discharge, SEst2 = Self Esteem post-discharge, SS1 = Social Support pre-discharge, SS2 = Social Support post-discharge,MF1 = Motor Function pre-

discharge, F2 = Motor Function post-discharge, Bal1 = Balance pre-discharge, Bal2 = Balance post-discharge

There was a significant correlation between CR and each of MF1 $(\mathrm{r}=0.53), \mathrm{MF} 2(\mathrm{r}=0.75)$, Bal1 $(\mathrm{r}=0.55)$ and $\mathrm{Bal} 2(\mathrm{r}=0.76)$. A significant positive correlation was found between $\mathrm{CR}$ and each of FSE1 $(r=0.62)$, BSE1 $(r=0.58)$, SEst1 $(r$ $=0.34)$ and SS1 $(r=0.29)$. Similarly, CR was significantly correlated with FSE2 $(\mathrm{r}=0.74)$, BSE2 $(r=0.59)$ and SS2 $(r=0.42)$. After adjusting for participants' socio-demographics and clinical characteristics (study location, age, gender, occupation, duration of stay in hospital, duration of physiotherapy before discharge, stroke laterality, type of stroke and number of stroke occurrence), all the variables remained significantly correlated with CR except SEst1, SEst2, SS1 and SS2 (Table 3).

A multiple regression model was generated to predict community reintegration from age and the pre-discharge variables that were significantly correlated with community reintegration after adjustment (MF1, Bal1, FSE1 and BSE1). This pre-discharge model significantly predicted community reintegration $\left(\mathrm{F}_{5,46}=13.64, \mathrm{p}=\right.$ $\left.<0.001, \mathrm{R}^{2}=0.60\right)$. However, only age $(\beta=$ $0.226, \mathrm{p}=<0.001)$ and FSE1 $(\beta=1.387, \mathrm{p}=$ 0.040 ) added significantly to the prediction (Table 4). Also, a second multiple regression model was generated to predict community reintegration from age and the post-discharge variables that were significantly correlated with community reintegration after adjustment (MF2, Bal2, FSE2 and BSE2). This post-discharge model also significantly predicted community reintegration $\left(\mathrm{F}_{5,46}=23.23, \mathrm{p}=<0.001, \mathrm{R}^{2}=0.72\right)$. Age $(\beta=-$ $0.164, p=0.005), \operatorname{Bal} 2(\beta=0.142, p=0.034)$, and FSE2 $(\beta=1.387, p=0.040)$ added significantly to the prediction (Table 4 ).

DOI: http://dx.doi.org/10.4314/ejhs.v27i1.5 
Table 3: Correlation between Community Reintegration and the Psychosocial/Clinical Attributes $(\mathrm{N}=$ 52) with and without Adjustment of Physical Characteristics.

\begin{tabular}{|c|c|c|c|c|}
\hline \multirow{3}{*}{ VARIABLE } & \multicolumn{4}{|c|}{ TYPE OF CORRELATION } \\
\hline & \multicolumn{2}{|c|}{ Full Correlation (Pearson) } & \multicolumn{2}{|c|}{ Partial Correlation } \\
\hline & $\mathbf{r}$ & $\mathbf{p}$ & $\mathbf{r}$ & $\mathbf{P}$ \\
\hline FSE1 & 0.624 & $<0.001 *$ & 0.493 & $0.001 *$ \\
\hline FSE2 & 0.742 & $<0.001 *$ & 0.609 & $<0.001 *$ \\
\hline BSE1 & 0.576 & $<0.001 *$ & 0.438 & $0.003 *$ \\
\hline BSE2 & 0.598 & $<0.001 *$ & 0.311 & $0.042 *$ \\
\hline SEst1 & 0.349 & $0.011^{*}$ & 0.106 & 0.500 \\
\hline SEst2 & 0.415 & $0.002 *$ & 0.239 & 0.122 \\
\hline SS1 & 0.287 & $0.039 *$ & 0.192 & 0.218 \\
\hline SS2 & 0.380 & $0.005^{*}$ & 0.265 & 0.086 \\
\hline MF1 & 0.528 & $<0.001 *$ & 0.333 & $0.029 *$ \\
\hline MF2 & 0.748 & $<0.001 *$ & 0.569 & $<0.001 *$ \\
\hline BAL1 & 0.548 & $<0.001 *$ & 0.403 & $0.007 *$ \\
\hline BAL2 & 0.757 & $<0.001 *$ & 0.640 & $<0.001 *$ \\
\hline
\end{tabular}

$*=$ Significant correlation at $p=0.05$, FSE1 $=$ Fall Self Efficacy pre-discharge, SE2 $=$ Fall Self Efficacy post-discharge, BSE1 = Balance Self Efficacy pre-discharge, BSE2 $=$ Balance Self Efficacy post-discharge, SEst $1=$ Self Esteem pre-discharge, SEst2 $=$ Self Esteem post-discharge, SS1 = Social Support pre-discharge, SS2 = Social Support post-discharge, MF1 = Motor Function predischarge, MF2 = Motor Function post-discharge, Bal1 = Balance pre-discharge, Bal2 = Balance post-discharge

Table 4: Regression Model of Community Reintegration for the Predictor Variables Pre-Discharge and Post-Discharge $(\mathrm{N}=52)$.

\begin{tabular}{|c|c|c|c|c|c|c|c|}
\hline \multirow{2}{*}{$\begin{array}{l}\text { Model } \\
\text { no }\end{array}$} & \multicolumn{3}{|c|}{ Model Summary } & \multirow{2}{*}{$\begin{array}{l}\text { Predictor } \\
\text { variables }\end{array}$} & \multirow[t]{2}{*}{$\boldsymbol{\beta}$} & \multirow[t]{2}{*}{$\mathbf{t}$} & \multirow[t]{2}{*}{ Sig. } \\
\hline & $\overline{\mathbf{R}^{2}}$ & df & F (sig) & & & & \\
\hline \multirow{5}{*}{1} & \multirow{5}{*}{0.60} & \multirow{5}{*}{5,46} & \multirow{5}{*}{$13.64(<0.001)$} & AGE & -0.226 & -4.312 & $<0.001^{*}$ \\
\hline & & & & MF1 & 0.024 & 0.518 & 0.607 \\
\hline & & & & BAL1 & 0.042 & 0.598 & 0.553 \\
\hline & & & & FSE1 & 1.387 & 2.113 & $0.040 *$ \\
\hline & & & & BSE1 & 0.014 & 0.210 & 0.834 \\
\hline \multirow{5}{*}{2} & \multirow{5}{*}{0.72} & \multirow{5}{*}{5,46} & \multirow{5}{*}{$23.23(<0.001)$} & AGE & -0.164 & -2.932 & $0.005^{*}$ \\
\hline & & & & MF2 & 0.049 & 1.354 & 0.182 \\
\hline & & & & BAL2 & 0.142 & 2.035 & $0.048 *$ \\
\hline & & & & FSE2 & 1.243 & 2.183 & $0.034 *$ \\
\hline & & & & BSE2 & 0.022 & 0.538 & 0.593 \\
\hline
\end{tabular}

$*$ Significant predictor at $\mathrm{p}=0.05$, FSE1 $=$ Fall Self Efficacy pre-discharge, FSE2 $=$ Fall Self Efficacy post-discharge, BSE1 = Balance Self Efficacy pre-discharge, BSE2 = Balance Self Efficacy post-discharge, SEst1 = Self Esteem pre-discharge, SEst2 = Self Esteem post-discharge, SS1 = Social Support pre-discharge, SS2 = Social Support post-discharge, MF1 = Motor Function predischarge, $\quad$ MF2 = Motor Function post-discharge, Bal1 = Balance pre-discharge, $\mathrm{Bal} 2=$ Balance post-discharge

\section{DISCUSSION}

A total of 52 stroke survivors from three tertiary hospitals in Nigeria participated in this study. The majority of the participants had ischaemic stroke approximately ratio of $3: 1$. This is incongruence with other studies which reported that the incidence of ischaemic strokes is more than haemorrhagic strokes (16-18).
About $60 \%$ of the variation in community reintegration of the participants could be explained by age and the pre-discharge motor function, balance, fall self-efficacy and balance self-efficacy while $75 \%$ of the variability in community reintegration could be explained by age and postdischarge motor function, balance, fall selfefficacy and balance self-efficacy. This implies that the CR at three months post-discharge can be predicted from the stroke survivor's age, motor

DOI: http://dx.doi.org/10.4314/ejhs.v27i1.5 
function, balance and fall self-efficacy at the point of discharge from in-hospital admission. However, $\mathrm{CR}$ is better predicted from the values of these variables obtained at three months post-discharge. When all other variables were held constant, age negatively varied with CR by 0.2 . This suggests a 0.2 unit decrease in $\mathrm{CR}$ with each successive increase in age. Thus, the older a stroke survivor, the more challenging it is for him/her to participate in the community.

Fall self-efficacy (pre-discharge and postdischarge) significantly and positively correlated with community reintegration and remained so even after adjustment for the influence of demographic characteristics. This suggests that stroke survivors with greater confidence against falling had better chances of reintegrating into their communities. Post-hoc regression model revealed that fall related self-efficacy is the strongest predictor of CR among other variables in the models. For a unit increase in the score of fall related self-efficacy pre-discharge, there is expected 1.4 fold increase in CR three months post-discharge. There appears to be a dearth of studies on the direct relationship between fall selfefficacy and community reintegration. Nonetheless, studies (19-23) have shown a relationship between fall self-efficacy and some measures of activities/participation among stroke survivors. In a study by Hellstrom and colleagues (23), fall self-efficacy was reported as a powerful predictor of activities of daily living. Therefore rehabilitation measures should be targeted at improving fall related self-efficacy, and consequently, the community reintegration among stroke survivors. Performance accomplishment, vicarious experience, verbal persuasion and improved physiological states have been reported to be effective in improving self-efficacy $(24,25)$.

Community reintegration was positively, significantly correlated with balance self-efficacy pre- and post-discharge even after adjustment for the physical characteristics of the patients. This suggests that stroke survivors with better balance confidence at the time of discharge and thereafter had a better chance of being reintegrated into the communities. Earlier studies had reported similar findings $(19,22,25)$. In a study by Pang et al (22) on the determinants of satisfaction with community reintegration in chronic stroke, balance self-efficacy showed the highest correlation with community reintegration. Although evidence has shown balance selfefficacy (BSE) as a significant predictor of stroke related activities and participation (26), post-hoc regression analysis in the our study showed that BSE was not a significant independent predictor of CR. Differences in time since stroke onset in the study of Salbach and co-workers (26) study and ours may account for the variation in findings. The participants in their study were chronic stroke survivors while the participants in the current studies were acute and post-acute stroke survivors. Also, differences in design and outcome measures may be responsible for the disparity in reports. However, this relationship needs to be explored to further delineate the effect of balance self-efficacy on community reintegration.

There was a significant positive correlation between self-esteem and community reintegration. However, after adjustment for the patients' physical characteristics, self-esteem was no longer significantly correlated with community reintegration. Studies $(28,29)$ have shown that low self-esteem has no direct effect on activity/participation. It has been suggested that the negative effect of self-esteem on participation restriction manifests as depressive symptom (28).

The pre-discharge and post-discharge social support scores of the participants were significantly and positively correlated with community reintegration. This suggests that the social support received by a stroke patient is important in the overall recovery and eventual reintegration of survivors into the community. This is in line with the findings of previous studies $(30,31)$ which indicated that improved social support aided the recovery of post-stroke patients. However, after adjustment for the participants' physical characteristics, both the pre-discharge and post-discharge social support scores were no longer significantly correlated with community reintegration. This implies that the influence of social support on community reintegration is dependent on the physical characteristics of the stroke survivors such as age and marital status.

Pre- and Post-discharge Motor Function (MF) scores were significantly and positively correlated

DOI: http://dx.doi.org/10.4314/ejhs.v27i1.5 
with community reintegration among the stroke survivors. This correlation was maintained even after adjusting for the participants' physical characteristics. This indicates that improvement in motor function of stroke survivors leads to improved reintegration into their communities. This agrees with earlier studies on the relationship between motor function and indices of participation (32-34). However, multiple regression analysis revealed that $\mathrm{MF}$ is not an independent predictor of community reintegration. Pang et al (22) similarly reported that motor function was not a significant predictor of community reintegration.

Balance scores at pre-patient discharge and at three months post-discharge significantly correlated with community reintegration of the participants even after adjusting for their physical characteristics. This implies that improved balance function results in better reintegration into the community after stroke. The findings of this study are similar with previous findings $(32,34,36)$. Although the pre-discharge balance score did not initially predict $\mathrm{CR}$ significantly, post-discharge balance score was a significant predictor of CR. Reports on the predictability of CR from balance appear conflicting. Schimd et al, (27) posited that balance was not an independent predictor of participation. Pang et al, (23) on the other hand found balance an independent predictor of community reintegration. The differences in the findings from those studies may be related to differences in study designs and characteristics of the study samples. There is a need for more studies to further elucidate the relationship between balance and activity/participation.

In conclusion, the findings of this study have shown that age, balance and fall self-efficacy were important predictors of community reintegration among stroke survivors three months after inhospital discharge. Therefore, rehabilitation programme for patients with stroke should include interventions aimed at improving balance and fall self-efficacy in order to promote community reintegration among survivors.

\section{REFERENCES}

1. Pollard B, Dixon D, Dieppe P, Johnston M. Measuring the ICF Components of Impairment,
Activity Limitation and Participation Restriction: An Item Analysis using Classical Test Theory and Item Response Theory. Biomed Central (Open Access). 2009; 7: 41 - 60.

2. Ogun SA, Adelowo OO, Familoni OB, Jaiyesimi AE, Fakoya EA. Pattern of Medical Admission at Ogun State University Teaching Hospital - A Three Year Review. West Afri J Med. 2000; 19:304 -7.

3. Ojini FI, Danesi MA. Pattern of Neurological Admissions at the Lagos University Teaching Hospital. Niger J Clin Pract. 2003; 5:38-41.

4. Teasell R., Foley N, Saltier K, Bhogal S, Bayona $\mathrm{N}$, Jutai J, et al. Background concept in stroke rehabilitation. Evidence Based Review of Stroke Rehabilitation. 2004; Module 3.

5. Trigg R, Wood VA. The Subjective Index of Physical and Social Outcome (SIPSO): a new measure for use with stroke patients. Clin Rehabil. 2000; 14(3): 288-99.

6. World Health Organization. The International Classification of Functioning, Disability and Health Geneva: World Health Organization; 2008.

7. Bhogal SK, Teasell RW, Foley NC, Speechley MR. Community Reintegration after Stroke. Top Stroke Rehabil. 2003; 10(2):107-29.

8. Vincent C, Deaudelin I, Robichaud L, Rousseau J, Viscogliosi C, Talbot LR, et al. Rehabilitation needs for older adults with stroke living at home: perception of four populations. Biomed Central Geriatrics. 2007; 7:20.

9. Wood-Dauphine SL, Williams JI. Reintegration to Normal Living Index as a Proxy to Quality of Life. J Chronic Dis. 1987; 40: 491 -502.

10. Heatherton TF, Polivy J. Development and Validation of a Scale for Measuring State SelfEsteem. J Pers Soc Psychol. 1991; 60(6):895.

11. Sarason IG, Levine HM, Bashman RB, Sarason BR. Assessing Social Support - The Social Support Questionnaire. J Pers Soc Psychol. 1983; 44(1): 127-39.

12. Powell LE, Myers AM. The Activities - Specific Balance Confidence (ABC) Scale. J Gerontol. 1995; 50: 28-34.

13. Tinetti ME, Richman D, Powell L. Falls efficacy as a measure of fear of falling. J Gerontol. 1990; 45: 239-243.

14. Fugl-Meyer AR, Jaasko L, Leyman I, Olsson S, Steglind S. The Post-Stroke Hemiplegic Patient: A Method for Evaluation of Physical

DOI: http://dx.doi.org/10.4314/ejhs.v27i1.5 
Performance. Scand J Rehabil Med. 1975; 975(7): 13-31.

15. Berg K, Wood-Dauphinee S, Williams JI, Gayton D. Measuring Balance in the Elderly: Preliminary Development of an Instrument. Physiother Can. 1989; 41:304-11.

16. Khan M, Ahmed B, Ahmed M, Najeeb M, Raza E, Khan F, et al. Functional, Cognitive and Psychological Outcomes and Recurrent Vascular Events in Pakistani Stroke Survivors: A Cross Sectional Study. BMC Research Notes. 2012; 5:89.

17. Schmid AA, Van Puymbroeck M, Knies K, Spangler-Morris C, Watts K, Damush T et al. Fear of Falling Among People Who Have Sustained a Stroke: A 6-Month Longitudinal Pilot Study. Am J Occup Ther. 2011; 65(2):.

18. Zhu HF, Newcommon NN, Cooper EE, Green TL, Seal B, Klein G, et al. Impact of a Stroke Unit on Length of Hospital Stay and In-Hospital Case Fatality. Stroke. 2009; 40:18-23.

19. Pang M, Eng J. Fall-Related Self-Efficacy, not Balance and Mobility Performance is related to Accidental Falls in Chronic Stroke Survivors with Low Bone Mineral Density. Osteoporos Int. 2008;19 (7): 919-27.

20. Andersson A, Kamwendo K, Appelros P. Fear of Falling in Stroke Patients: Relationship with Previous Falls and Functional Characteristics. Int J Rehabil Res. 2008; 31 (3): 261-4.

21. Hamzat TK, Kobiri A. Effects of Walking with a Cane on Balance and Social Participation among Community-dwelling Post-stroke Individuals. Eur J. Phys Rehabil Med. 2008; 44: 121-6.

22. Pang MY, Eng JJ, Miller WC. Determinants of Satisfaction with Community Reintegration in Older Adults with Chronic Stroke: Role of Balance Self-Efficacy. Phys Ther. 2007; 87:282-91.

23. Hellstrom K, Lindmark B, Wahlberg B, FuglMeyer AR. Self-Efficacy in relation to Impairments and Activities of Daily Living Disability in Elderly Patients with Stroke: A Prospective Investigation. J Rehabil Med. 2003; 35: 202-7.

24. Bandura A. Social foundations of thought and action: A social cognitive theory. Englewood Cliffs, NJ: Printence Hall; 1986.

25. Bandura A. Self-efficacy: The exercise of control. New York: W. H. Freeman 1997.

26. Salbach NM, Mayo NE, Robichaud- Ekstrand S. Balance Self-Efficacy and its Relevance to
Physical Function and Perceived Health Status after Stroke. Arch Phys Med Rehabil. 2006; 87:364-70.

27. Schmid AA., Van Puymbroeck M, Altenburger PA, Dierks TA, Miller KK, Damush TM, et al. Balance and Balance Self-Efficacy are associated with Activity and Participation after Stroke: A Cross-Sectional Study in People with Chronic Stroke. Arch Phys Med Rehabil. 2012; 93:1101-7.

28. Chau JP, Thompson DR, Twinn S, Chang AM, Woo J. Determinants of Participation Restriction among Community Dwelling Stroke Survivors: A Path Analysis. BMC Neurology. 2009; 9:49

29. Chang AM, Mackenzie AE. State Self-Esteem Following Stroke. Stroke. 1998; 29: 2325-28.

30. Beckley MN. Community Participation Following Cerebrovascular Accident: Impact of the Buffering Model of Social Support. Am J of Occup Ther. 2006; 60, 129-35.

31. Hegelson VS. Social Support and Quality of Life. Qual Life Res. 2003; 12, 25-31.

32. Murtezani A, Hundozi H, Gashi S, Osmani T, Krasniqi V, Rama B. Factors Associated with Reintegration to Normal Living After Stroke. Med Arch. 2009; 63(4): 216-9.

33. Ostwald SK, Swank PR, Khan MM. Predictors of Functional Independence and Stress Level of Stroke Survivors at Discharge from Inpatient Rehabilitation. J Cardiovasc Nurs. 2008; 23(4):371-7.

34. Hamzat TK, Peters GO. Motor function and participation among Nigerian stroke survivors: 6-Month follow-up study. NeuroRehabil. 2009; 25(2): $137-42$.

35. Fernandes B, Prates L, Ferreira MJ, Beckert P, Evangelista I, Sergio1 JS. Relationship of Balance to Functional Independence in Stroke Survivors. American College of Sports Medicine's 57th Annual Meeting, Baltimore, Maryland. 2010.

36. Alzahrani MA, Dean CM, Ada L, Dorsch S, Canning CG. Mood and Balance are Associated with Free-Living Physical Activity of People after Stroke Residing in the Community. Stroke Res Treat. 2011; 20(12): 60.

DOI: http://dx.doi.org/10.4314/ejhs.v27i1.5 